\title{
“NO CENTRO DO SERTÃO, O QUE É DOIDEIRA ÀS VEZES PODE SER A RAZÃO”, OU SOBRE FORMAÇÃO EM FILOSOFIA E COLONIALISMO
}

\section{Roberto Rondon*}

\begin{abstract}
Resumo: O objetivo desse artigo é discutir algumas questões relacionadas à Filosofia e formação filosófica, relacionando-as com o desenvolvimento do colonialismo em nosso meio. O que apontamos aqui é que, ao invés dos repetidos lamentos de que a ausência da Filosofia em nosso sistema de ensino se deveu ao seu caráter crítico e radical, e que os governantes sempre a deixaram de fora da educação popular ou pública por receio de que "o povo pensasse", nossa desconfiança é que seu lugar foi o de um conhecimento colonizado e reprodutor do pensamento metropolitano, e que sempre distinguiu as classes economicamente superiores e as camadas médias da "intelligentsia", das bárbaras massas populares.
\end{abstract}

Palavras-Chave: Colonialismo; Classes Sociais; Educação, Filosofia, Ensino de Filosofia

Resumen: El propósito de este artículo es discutir algunos temas relacionados con la filosofía y la formación filosófica, relacionándolos con el desarrollo del colonialismo en nuestro entorno. Lo que señalamos aquí es que, en lugar de los repetidos lamentos de que la ausencia de Filosofía en nuestro sistema educativo se debió a su carácter crítico y radical, y que nuestras élites siempre lo han dejado fuera de la educación popular o pública por miedo a que "la gente pensó", nuestra sospecha es que su lugar era el de un conocimiento colonizado que reproducía el pensamiento metropolitano, y que siempre distinguía a las clases económicamente superiores y las capas medias de la "intelectualidad", de las masas populares bárbaras.

Palabras Claves: Colonialismo; Clases Sociales; Educación, Filosofía, Enseñanza de la Filosofía.

Quando, com humildade de "cabecitas negras", compreendam que eles também são no mundo "cabecitas negras", e que o esforço intelectual consiste em dar uma, cada vez mais alta, expressão aos "cabecitas negras"

Arturo Jauretche

A primeira imagem que nos vêm à cabeça ao começarmos a escrever esse texto é a do atual presidente do Brasil, numa manifestação recente com seus apoiadores, tendo como fundo as bandeiras de Israel e dos Estados Unidos.

A primeira é a pátria de um povo que teve papel marcante e muitas vezes silenciosa (e silenciada) em nossa história, desde a

\footnotetext{
* Professor de Filosofia da Educação da UFPB e do Mestrado Profissional em Filosofia, núcleo da UFCG. Pesquisador do Núcleo de Estudos Filosofia e Infâncias-UERJ.
}

usurpação das terras indígenas no processo de colonização, sejam como financiadores desses projetos ${ }^{2}$; tripulantes das frotas conquistadoras; invasores de territórios e criadores de povoamentos e cidades para a metrópole; assim como a debatida questão sobre a origem judaica de Colombo. Essa presença se estende fortemente até hoje entre nossa elite, basta olharmos a lista das principais fortunas do Brasil, veremos no topo sobre-

\footnotetext{
${ }^{2}$ Como o banqueiro Luis de Santángel, financiador das expedições de Colombo.
}

RONDON, Roberto. "No centro do sertão, o que é doideira às vezes pode ser a razão", ou sobre formação em filosofia e colonialismo. Revista Sul-Americana de Filosofia e Educação. Número 34: nov. 2020 - abril 2021, p. 34-42. DOI: https://doi.org/10.26512/resafe.v2i34.35130 
nomes como Safra, Lemann, Hermann, entre outros.

Acreditamos que a presença da outra bandeira dispense comentários, pois essa se manifesta desde os tempos do senador estadunidense Francis Preston, que dizia, em 1838, sonhar com o dia em que "a bandeira estrelada flamejará sobre toda a América Latina até a Terra do Fogo, único limite que reconhece a ambição de nossa raça" (UGARTE, 1923, p. 7);

Ilustramos nosso texto com essa imagem, para situarmos o conceito central que acreditamos ser central para compreendermos esses acontecimentos: a permanência do Colonialismo, pois, partilhando a visão dos autores que participam de nossa reflexão, o consideramos como marco central do desenvolvimento da Iberoamérica, desde as invasões por parte das comunidades de Castela e Aragão aos impérios e aos povos aqui existentes no século $\mathrm{XV}$, até a configuração de nossas economias contemporâneas, na era do capitalismo financeiro e digital.

Fenômeno complexo que se desenvolveu nos últimos séculos, em conjunto com a ascensão da modernidade e do capitalismo, e que configurou nossas relações políticas, sociais, econômicas e culturais a partir dos interesses e valores das elites dos países colonizadores, ora pela diplomacia, ora pela força, de acordo com a conjuntura do momento, formando uma complexa combinação que abrange o já mencionado atrelamento às metrópoles por nossa classe dominante local; a participação de uma camada média urbana recente, que esvaziada da percepção de lugar e de classe, reproduz os sonhos de felicidade do norte; e uma imensa maioria de povos expropriados de seus direitos mínimos, condenados a lutar cotidianamente pela subsistência.

Claro que esse processo não se construiu sem resistências, pois desde o momento das guerras de conquista elas se expressaram através de movimentos políticos e sociais muito diversos. Porém, o que não conseguimos foi afirmar nossa identidade plural com os outros povos colonizados do continente. Pelo contrário, o que as metrópoles (primeiro a Inglaterra e depois os Estados Unidos) conseguiram foi alimentar rivalidades fúteis e artificiais entre nossas populações, incentivadas pelas elites locais, numa tentativa de apagamento dos traços comuns de nossas culturas e desenvolvimento, na busca de favorecer seus interesses econômicos e de controle. Não se entende a balcanização geopolítica de nosso continente, sem perceber esse processo.

Pelo menos desde os movimentos de independência, alguns intelectuais (escritores, juristas, poetas), através de seus escritos e ações, buscaram compreender e enfrentar as causas dessa situação. Simón Rodríguez, José Martí, Torres Caicedo, Haya de La Torre, Manuel Bonfim, Lima Barreto, Manuel Ugarte, José Rodó, entre outros, puseram em questão o problema do colonialismo $e$ do nosso lugar no continente e no mundo. Muitos deles almejaram a possibilidade da reconstrução da sonhada Pátria Grande, como uma grande federação dos povos iberoamericanos, como única possibilidade de (r)existência de nossos povos.

Cabe destacar que a maioria deles é desconhecido no meio acadêmico brasileiro, a não ser nos poucos grupos que se dedicam a estudar a América Latina, o que gera uma grande lacuna em nossa formação e revela 
com toda a força os processos coloniais que se materializam também em nossos centros educacionais

Mas voltando aos resistentes, o escritor argentino Manuel Ugarte ${ }^{3}$, afirmava numa carta da década de 1940, escrita no Chile:

Para os fundadores da Pátria - Bolívar, San Martin, O'Higgins, Morazán - a liberdade se traduziu em sacrifício. Os que esforçando-se por seguir suas influências, trataram mais tarde de favorecer a nossos países, tiveram parecida sorte. Suicidou-se Balmaceda, que tentou a organização nacional no Chile, como se suicidou Lisandro de La Torre, que denunciou, na Argentina, os abusos dos frigoríficos estrangeiros.

Até os teóricos inofensivos se viram obrigados, se investigarmos bem, a passar a fronteira. A morte miserável de José Enrique Rodó na Itália, mais que obra da casualidade, foi consequência de seu livro Ariel.

Por haver empreendido há trinta anos uma campanha em favor da independência integral de Iberoamérica, quem escreve estas linhas se acha condenado ao ostracismo. (UGARTE apud GALASSO, 2019, p.98)

A partir da década de 1930 vemos renascer a construção de projetos nacionais autônomos em muitos governos que se instauraram na região. Os exemplos de Lázaro Cárdenas, no México; Juan José Arevalo, na Guatemala; Juan Bosch, na República Dominicana; Perón, na Argentina; Getúlio Vargas, no Brasil; além, é claro, da Revolução

\footnotetext{
${ }^{3} \mathrm{O}$ próprio Manuel Ugarte se suicidou autoexilado na
} Suiça, em 1951.
Cubana de Fidel e Che Guevara, são alguns que, com todas suas contradições, apontavam um novo caminho para seus países $e$ influenciaram toda uma geração posterior a partir dessas experiências.

Esses novos movimentos, que propunham outros olhares para a Iberoamérica, mas também a forma com que foram interrompidos, geraram a reflexão de uma nova geração importante de intelectuais por todo o cone sul do continente, que buscavam entendê-los e enfrentá-los em toda a sua complexidade. A partir de então, autores como Arturo Jauretche, Hernandez Arregui, Jorge Abelardo Ramos, Jorge Spilimbergo, Álvaro Vieira Pinto, Darcy Ribeiro, além dos próprios protagonistas dessas experiências, construíram novas perspectivas para o entendimento dos processos de permanência da lógica colonial em nosso meio, e suas respectivas formas de superação.

Do ponto de vista conceitual, esses autores podem ser enquadrados naquilo que se consolidou chamar como "Nacionalismo Revolucionário" (ou na sua versão nacional de um "Socialismo Moreno", na feliz imaginação de Darcy Ribeiro), por reunir elementos que recolocavam a interpretação da história e da cultura nacional, a partir de uma perspectiva revolucionária, anticolonial, iberoamericanista e socialista, questionando a visão liberal, predominante tanto nos "Gansos do Capitólio"4; como no radicalismo vazio de uma "esquerda internacionalista abstrata", dessas que ainda vendem seus jornaizinhos nas universidades e manifestações.

Apontando para o imperialismo bélico e econômico, eles percebem que, para

\footnotetext{
${ }^{4}$ Conforme a definição de ARÉVALO (1959).
} 
além desses, e de maneira também eficiente, se dá o colonialismo pedagógico e cultural.

Como afirma Jauretche:

quando os impérios exercem o domínio político diretamente, este se impõe pela persuasão da artilharia que, logicamente, é categórica; porém, quando o domínio prefere manter a ficção da autonomia jurídica, a aparência da soberania, a colonização se faz por meios indiretos: se maneja a inteligência, $e$ a habilidade consiste em criar uma pedagogia colonial, um modo de formação da inteligência para que a mesma não perceba a situação real $e$, mais ainda, seja sua colaboradora (JAURETCHE, 1973, p. 136).

A educação formal foi um dos lugares onde isso ocorreu de maneira mais evidente, pois passados os arroubos libertários dos projetos independentistas, frutos do calor das lutas e das batalhas travadas por nossos libertadores e libertadoras e seus exércitos mestiços, o que prevaleceu nas colônias liberadas foi a consolidação das estruturas políticas e econômicas das metrópoles representadas nos ideais liberais de República, Democracia, Liberdade, Constituição, Estado, entre outros.

Se há algo que guiou os discursos de nossas elites, desde os nossos primeiros republicanos aos projetos neoliberais contemporâneos, é a falsa contradição entre civilização e barbárie, progresso e atraso, que nos coloca sempre como sociedades que necessitam superar etapas primitivas de desenvolvimento econômico, social e cultural para atingirmos os sonhados níveis dos países centrais.

Para tal empreendimento, uma das mais importantes instituições que se instituiu como lócus, por excelência, do desenvolvimento dos seres humanos adequados à construção dessas novas repúblicas e império (no caso brasileiro) foi a Escola. Idealizada a partir dos projetos educacionais da nascente escola moderna europeia, desde a estrutura dos prédios escolares, passando pelos currículos (centrados na língua, nas ciências, nas artes $e$ nas filosofias metropolitanas) $e$ métodos, que foram desenvolvidos a partir das ideias e práticas dos educadores franceses, ingleses e alemães (e mais tarde pelos estadunidenses). Seu objetivo era formar os filhos da classe dominante e "elevar" as camadas médias que iriam ocupar o aparato estatal, dando continuidade à produção econômica das novas nações aos patamares estabelecidos pelos modelos trazidos de além-mar.

Como bem aponta Martin Carnoy:

Ao ver-se na instrução escolar um importante componente da educação, e que dura toda a vida, muitos deduzem que a população de uma nação é ignorante ou inculta se frequentou pouco a escola. As nações chegaram a crer que, para ser aceitas como civilizadas, tem que ser instruídas, e que para ser instruídas, tem que ter havido escola (CARNOY, 2000, p.12).

Os caipiras, caiçaras, gaúchos, andinos, cholas, "cabecitas negras", sertanejos, negros e indígenas - os eternos responsáveis por nosso atraso por suas características étnicas ou culturais - deveriam - e devem - ser formados dentro dos moldes do projeto civilizatório do homem médio das sociedades europeias e seus ideais de cultura e civilização. Para isso, implementou-se historicamente um processo de negação dessas populações, seja pela desvalorização e até a proibição de suas línguas, saberes e costumes mais profundos; seja pela imposição de 
valores e conhecimentos dos colonizadores. Assim, "a imensa maioria da minúscula minoria proporção de não europeus muito cultos dos países colonizados decidiu emular aos europeus e deixar para trás seu próprio povo." (CARNOY, 2000, p. 30)

Nesse ponto, podemos perceber $e$ problematizar a Filosofia como lugar $e$ instrumento privilegiado desse ideário de "civilização", que se contrapõe a outras formas de conhecimentos originários, tidos como bárbaros e responsáveis por nosso "atraso" em relação às metrópoles.

O que apontamos aqui é que, ao invés dos repetidos lamentos de que a ausência da Filosofia em nosso sistema de ensino se deveu ao seu caráter crítico e radical, e que os governantes sempre a deixaram de fora da educação popular ou pública por receio de que "o povo pensasse", nossa desconfiança é que seu lugar foi o de um conhecimento colonizado e reprodutor do pensamento metropolitano, e que sempre distinguiu as classes economicamente superiores e as camadas médias da "intelligentsia", das bárbaras massas populares. Nunca é demais lembrar que só em 2008 , num governo que contou com a forte participação de setores populares, é que se universalizou o ensino da Filosofia por toda o sistema regular de ensino nacional, mas mesmo assim com a forte reprovação de parte da comunidade filosófica que afirmava que isso iria "popularizar" ou "empobrecer" (aqui como sinônimos de degradar, corromper) "a" Filosofia. Claro que, mesmo participando do entusiasmo pelo enorme avanço dessa medida, destacamos que ela se instalou atrelada e subordinada aos princípios fundamentais de nossa Lei de Diretrizes e Bases da Educa- ção, de 1996, quais sejam, a formação de pessoas para a cidadania (conjunto de características daqueles que habitam a civitas, a polis, a cidade, em oposição ao mundo rural sempre vinculado às tradições ancestrais, consideradas atrasadas no tempo do futuro $e$ da velocidade); e para o trabalho (alienado $e$ heterônomo do mundo capitalista).

Através dos tempos, seja na educação religiosa, e depois em sua forma laica, ela funcionou como instrumento de formação de nossa elite e reprodutora da cultura europeia. Portanto, não causa estranheza os questionamentos e críticas do ministro da educação brasileiro, Abraham Weintraub, sobre a presença de cursos superiores de Filosofia gratuitos e, ainda mais, nas Universidades Públicas do Nordeste. Longe de ser uma aberração, elas refletem a forma histórica da construção - real e simbólica - da Filosofia em nosso meio ${ }^{5}$.

Primeiro, concentrados nas discussões sobre a existência de Deus, ou, mais tarde, de justiça e direito em Kant e Comte, nossos filósofos aprendizes animavam-se nos bares e cafés mantidos pelo trabalho dos bárbaros escravos e mestiços inferiores.

Nossos filósofos, como afirma Jauretche (1973, p. 148), tomaram como valores universais a valores locais, "cuja aparência de universalidade surge exclusivamente do poder de expansão universal que lhes dão os centros onde nascem, com a irradiação que surge de seu caráter metropolitano." $\mathrm{E}$ acrescenta, "tomar como absoluto esses valores relativos é um defeito que está na gê-

\footnotetext{
${ }^{5}$ https://josiasdesouza.blogosfera.uol.com.br/2019/04/ 08/universidade-nordestina-nao-deve-ensinarfilosofia-diz-novo-titular-do-mec/ Acesso em 26/05/2020. Tiramos o que estava sublinhado.
} 
nese de nossa 'intelligentsia' ${ }^{6}$ e daí seu colonialismo".

Isso porque, nesse pretenso universalismo da Filosofia, seus iniciados são convidados a sentirem-se pertencentes à pátria universal dos filósofos, esse lugar que os coloca em casa nas ruas imaginárias de Atenas ou do Quartier Latin, mas sempre deslocados em Sumé, em Primavera do Leste, no Valle Encantado, ou em "La Caro", desconsiderando sua identidade a partir das questões geográficas ou históricas, onde acontece a vida real.

Mas, ora, muitos poderão dizer que isso se passava numa configuração de uma filosofia tradicional e conservadora. Porém, também nos filósofos contemporâneos adeptos das filosofias "críticas" ou "pós críticas", observamos o mesmo discurso sobre uma missão e um lugar do filósofo, e do professor de filosofia, de levar esse nobre conhecimento às classes excluídas, como forma de emancipá-las das trevas da ignorância ou da "sociedade do controle" em que estão inseridas. Nesses "pós" platonismos", entram menções a Marx, Nietzsche, Gramsci, Foucault, Deleuze, Adorno, Beauvoir, Butler, Agambem, Zizek, ou qualquer neo revolucionário da moda em Paris, Berlim, ou Nova Iorque.

Dentro desse quadro, o que ocorre então com nossos aprendizes de filósofos quando entram nas academias? Que tipo de estudantes são gerados dentro dessa mentalidade, e que modelos levarão para as salas

\footnotetext{
${ }^{6}$ Jauretche utiliza essa expressão como forma irônica de caracterizar os intelectuais latino americanos que reproduzem os valores e interesses das metrópoles em detrimento de sua cultura e sociedade.
}

de aula quando formalmente habilitados como novos professores?

Para Jauretche, uma das consequências mais fortes dessa formação é o que ele chamava de "fubismo":

\begin{abstract}
um sentimento de superioridade intelectual que o leva a desprezar o povo. Os estudantes veem os trabalhadores rurais e os operários como fracassados. Não compreendem que os grandes mestres do mundo político, social e cultural nacional não estão na universidade, mas, precisamente, nessa multidão (JAURETCHE, 1973, p. 145).
\end{abstract}

Esse fenômeno originado pelo colonialismo pedagógico, se torna mais impressionante quando observamos que, na última década, a maioria dos estudantes dos cursos de Filosofia vêm exatamente das classes populares, mas acabam percebendo seu ingresso no mundo encantado da filosofia como acesso a uma superioridade intelectual e cultural sobre seus pares. Em nome de uma pretensa superação de sua condição de exclusão e menoridade intelectual (geralmente ilustrada por textos de Kant) - explicada por seu não acesso ao saber escolarizado - o que ocorre é a negação da rica diversidade cultural e de conhecimentos de nossa iberoamericana, levando-os a construírem uma imagem desvalorizada de sua própria cultura e conhecimentos, reforçando a afirmação de uma identidade local sempre inferiorizada, o que os força a buscar abandonar seus conhecimentos mais profundos oriundos de sua experiência social.

Neste sentido que legitimamente pode falar-se de uma verdadeira devas- 
tação espiritual das novas gerações. A juventude universitária, em particular, assimilou os piores traços de uma cultura antinacional por excelência. Sob estas condições históricas se formou nossa elite intelectual. (RAMOS apud JAURETCHE, 1973, p. 147).

Mais recentemente, para além dos muros da universidade, essa formação é reforçada pelas influências e modelos vindos da "intelligentsia" que abunda nos meios de comunicação: grandes jornais, sites, programas de rádio e televisão, que reforçam o discurso colonizado. Afinal, essas são financiadas pelas grandes empresas capitalistas, $e$ seu grau de autonomia anunciada na tão defendida "liberdade de imprensa", refere-se apenas a poder expressar livremente, e sem nenhum controle social, os interesses de seus anunciantes.

De um lado temos os já citados "Gansos do Capitólio", cujos "melhores grasnidos procedem da imprensa grande, da imprensa industrializada, a imprensa dos milionários para leitores eleitos" (AREVALOS, 1959, p. 147).

Essa imprensa de negócios, para atender a demanda das elites e das camadas médias universitárias, convoca alguns membros da "intelligentsia" universitária para legitimar simbolicamente o ponto de vista de seus patrocinadores. Obviamente que aqui se expressa a defesa mais bem-acabada dos interesses dos países centrais. Qualquer tentativa de constituição soberana de um governo latino-americano, que confronte os interesses das grandes corporações é apontada como populismo, atraso ou ditadura.
Por outro lado, para manter um ar de imparcialidade e objetividade, também são convocados por essas empresas alguns intelectuais "críticos" que com suas referências eurocêntricas tentam explicar os acontecimentos políticos de nossas sociedades.

Como aponta Jauretche, numa ironia extremamente atual, e que cabe com precisão a esses últimos:

Os intelectuais em política são assim. Primeiro estudam o catálogo e depois classificam, por analogia, o que veem em seu país. E quando há uma "pueblada", porque reinventam as correntes artificiais que outros doutores puseram à realidade, andam como as crianças buscando figurinhas difíceis, para nominá-las. $\mathrm{E}$, uma vez que lhes põe nomes, se acham os mais satisfeitos: cruzam os braços porque já sabem tudo. A última moda é chamar de fascismo ao que não entendem (JAURETCHE, 1973, p. 180).

Segue-se a isso a escrita de best sellers para abastecer o mercado editorial, cursos de pós graduação privados caríssimos $e$, mais recentemente, estendendo seu alcance para as novas megaempresas capitalistas como a Google (Youtube) e o Facebook (Instagram).

Bombardeados em suas salas de aula, nos livros que lhe são indicados e pelos meios de comunicação de massa, reproduz-se a formação das novas gerações de filósofos $e$ filósofas que seguirão o modelo de seus mestres e mestras, qual seja, a reprodução do pensamento colonial.

Porém, longe de nós querer concluir com isso que esse fenômeno não tem saída, brechas, ou possibilidades de ruptura. As 
ações de uma nova geração de estudantes $e$ professores que não encontram na escola, na universidade e na Filosofia o "seu mundo", e que buscam alternativas para superar essa condição, nos coloca num novo período de contestações aos modelos coloniais, seguindo os passos de muitos de nossos ancestrais. Isso tem levado a afirmação de suas identidades de classe, regionais, étnicas e de gênero, constituídas nos processos históricos e culturais da Iberoamérica, da (re)descoberta de toda essa tradição "maldita" dos que ousaram enfrentar o Império, além de uma nova produção cultural movida por suas experiências e criatividade, que já afirmam seu lugar nos currículos e práticas das escolas e universidades no continente. $^{7}$

Isso retoma alguns desafios já colocados pelo IX Congresso Interamericano de Filosofia, realizado em Caracas, em junho de 1977, que apontava algumas recomendações sobre o "Estudo da Filosofia na América Latina" e que, por sua pertinência, reproduzimos aqui:

Desde que se inicia no século XIX a gestação da liberação latinoamericana se coloca a necessidade de uma integração de nossos povos sob o signo da liberdade que substitua a obrigada integração derivada da dependência imposta pelo imperialismo. Sem dúvida, o desconhecimento que guardam entre si os povos latino-americanos têm sido um dos fatores que impedem o sucesso da desejada integração. Daí a necessidade de criar uma concepção autentica-

\footnotetext{
${ }^{7}$ Produções do Grupo de Trabalho "Filosofar e Ensinar a Filosofar", da ANPOF; pesquisas produzidas nos núcleos regionais do Mestrado Profissional em Filosofia; e artigos publicados nas revistas da área, são exemplos desse movimento.
}

mente latino-americana da cultura, a história do pensamento de nossos povos através de todos os níveis da educação, desde a primária à universidade; tal e como se faz com a história, cultura e pensamento nacional e universal (ZEA, 1978, p.5).

Cabe então um retorno ao local, ao regional ampliado numa perspectiva da nação latino-americana, como possibilidade de quebra do colonialismo pedagógico e filosófico implantado historicamente em nosso meio. A afirmação do comum, do local, do território, das particularidades, da unidade na diversidade de nossa cultura, não como barbárie ou atraso, mas como uma rica produção plural que nos identifica e dá possibilidades de interlocução com outras culturas na construção de novas relações da Vida.

Necessário retomar a sabedoria do jagunço/professor Riobaldo, que afirmava que "No centro do sertão, o que é doideira às vezes pode ser a razão mais certa $e$ de mais juízo!" (ROSA, 1994, p. 400)

Concluímos então com Jauretche, apontando que

O estudante - mas também os professores (RR) - se libera do "fubismo" quando começa a sentir-se homem antes que estudante, e filho do país $e$ irmão de seus irmãos, antes que membro de um setor magistral; quando o grupo social estudantil (ou professoral) começa a dissolver-se na multidão e sentir-se parte dela, compreendendo que somente aprende uma técnica que leva à profissão, como outras técnicas levam ao oficio, ao negócio, à empresa ou à granja. Em uma palavra, quando se demole sua condição de elite, e se 
rompe a pretensão tutorial da "intelligentsia", e o estudante percebe que ele não é a "civilização contra a barbárie", mas parte de uma sociedade real que nesse dilema lhe foi apresentada como bárbara. Quando começa a pensar como argentino (ou ibero americano) que é estudante, $e$ não como estudante, que apesar disso é argentino. Nesse momento então - creio que agora - perderá essa tosca atitude que o caracterizou fren- te aos movimentos autênticos das massas, que antes via, desde qualquer angulo ideológico - do liberal ao marxista - com os olhos desse confuso híbrido que é o fubismo nascido de sua localização na inteligência; quando com humildade se reintegra ao país abandonando seus "preconceitos culturais". (JAURETCHE, 1973, p. 204).

\section{Referências}

AREVALOS, J. Antikomunismo en América Latina. Buenos Aires: Palestra, 1959.

ARREGUI, Juan José Hernández. O que é o ser nacional? Rio de Janeiro: Paz e Terra, 1971.

CARNOY, M. La educación como imperialismo cultural. México: Siglo XXI, 2000.

GALASSO, N. Manuel Ugarte: un argentino maldito. Disponível em http://www.labaldrich.com.ar/wp-content/uploads/2013/03/Norberto-Galasso-Manuel-Ugarte.Un-Argentino-Maldito.pdf. Acesso em 15/09/2019.

JAURETCHE, A. Los profetas del ódio y la yapa. Buenos Aires: A. Peña e Lillo, 1973.

RAMOS, J. Historia de la nación latinoamericana. Buenos Aires: Ediciones Continente, 2011.

ROSA, G. Grande Sertão: Veredas. São Paulo: Nova Aguilar, 1994.

SPILIMBERGO, J. Nacionalismo oligárquico y nacionalismo revolucionário. Buenos Aires: Amerindia, 1956.

UGARTE, M. La Patria Grande. Buenos Aires: Capital Intelectual, 2010.

. El destino de un continente. Madrid: Hernández y Galo Sáez, 1923.

ZEA, L. Presentación. In: BOLIVAR, S. Cuadernos de cultura latino-americana. Vol. 1. México: UNAM, 1978. 